\title{
Lipid-mediated protein functionalization of electrospun polycaprolactone fibers
}

\author{
C. Cohn ${ }^{1}$, S. L. Leung ${ }^{2}$, J. Crosby ${ }^{1}$, B. Lafuente ${ }^{3}, Z . Z h a^{2}$, W. Teng ${ }^{2}$, R. Downs ${ }^{3}, X . W u^{1,2^{*}}$ \\ ${ }^{1}$ Biomedical Engineering Graduate IDP, University of Arizona, AZ 85721 Tucson, USA \\ ${ }^{2}$ Aerospace \& Mechanical Engineering, University of Arizona, AZ 85721 Tucson, USA \\ ${ }^{3}$ Department of Geosciences, University of Arizona, AZ 85721 Tucson, USA
}

Received 30 September 2015; accepted in revised form 16 December 2015

\begin{abstract}
In this study, electrospun polycaprolactone (PCL) fibers are plasma-treated and chemically conjugated with cholesteryl succinyl silane (CSS). In addition to Raman spectroscopy, an immobilization study of DiO as a fluorescent probe of lipid membranes provides evidence supporting the CSS coating of plasma-treated PCL fibers. Further, anti-CD20 antibodies are used as a model protein to evaluate the potential of lipid-mediated protein immobilization as a mechanism to functionalize the CSS-PCL fiber scaffolds. Upon anti-CD20 functionalization, the CSS-PCL fiber scaffolds capture Granta-22 cells 2.4 times more than the PCL control does, although the two fiber scaffolds immobilize a comparable amount of antiCD20. Taken together, results from the present study demonstrate that the CSS coating and CSS-mediated antibody immobilization offers an appealing strategy to functionalize electrospun synthetic polymer fibers and confer cell-specific functions on the fiber scaffolds, which can be mechanically robust but often lack biological functions.
\end{abstract}

Keywords: coatings, electrospun polycaprolactone fibers, cholesteryl succinyl silane, protein immobilization

\section{Introduction}

Nanofiber scaffolds, which are fabricated by using self-assembling (SA) $[1,2]$ or fiber-spinning techniques [3-6], resemble the fibrillar and mechanical characteristics of extracelullar matrix (ECM) and are extensively explored for their potential applications in tissue and cell engineering. Various strategies have been pursued to introduce bioactive functionalities into nanofiber scaffolds to recapitulate the biological properties of ECM. For instance, amino acid sequences that are derived from ECM proteins have been incorporated into SA nanofiber hydrogels via protein engineering or click chemistry, promoting cell-specific activities such as cell adhesion and proliferation [7-9]. Subsequently, biofunctions of amino acid sequences may be well retained, because SA nanofiber hydrogels are often prepared under cellcompatible conditions. Compared to SA nanofiber hydrogels, synthetic polymer scaffolds fabricated using fiber-spinning techniques may possess enhanced mechanical properties that are necessary for many applications [10]. ECM derived proteins such as gelatin [10-12] and collagen [13-15] may be cospun with synthetic polymers into nanofibers, and amino acid sequences or antibodies may be chemically conjugated onto synthetic polymer fibers [1618], rendering the fiber scaffolds biologically active. However, the selection of protein- or peptide-based functionalities that can be incorporated onto synthetic polymer nanofibers may be limited by the harsh conditions of fiber spinning or by the particular conjugation chemistry that only works for certain biomolecules.

Here, we envision that the coating of electrospun polycaprolactone (PCL) fibers with cholesteryl succinyl silane (CSS) and the subsequent CSS-mediated anti-

\footnotetext{
$\overline{{ }^{*} \text { Corresponding author, e-mail: xwu@email.arizona.edu }}$ (C) BME-PT
} 
body immobilization on the fibers may provide an appealing strategy to biologically functionalize mechanically robust polymer scaffolds that otherwise support little cell-specific activities. Previously, we have engineered CSS fibers that are capable of immobilizing membrane-bound antibodies and retaining the antibody's cell-binding functions [19]. Recently, we have demonstrated that the CSS fibers possess a greater ability to functionally immobilize antibodies for cell capture than the PCL and plasmatreated PCL fibers do [20]. However, our previous work illustrates that the CSS fibers lack tensile strength [21], limiting their applications in tissue and cell engineering. In contrast, electrospun PCL fibers are well known for their good mechanical strength, slow enzyme-mediated degredation, and minimal toxicity [22-24]. As a continuation of our recent work, CSS molecules are hydrolyzed in ethanol solutions with the addition of a small amount of water, and the hydrolyzed CSS molecules form lipid vesicles; electrospun PCL fibers are plasma-treated and incubated with CSS vesicles in ethanol, leading to the immobilization, rupture and fusion of CSS vesicles into a continuously supported lipid bilayer on PCL fibers. Membrane-bound proteins such as antibodies can be immobilized on the PCL fibers coated with the CSS bilayers (CSS-PCL fibers) via a lipid-mediated immobilization mechanism, conferring cellspecific activities on the fiber scaffolds. As a result, the CSS-PCL fibers integrate the mechanical strength of PCL fibers and the ability of CSS bilayers to functionally immobilize membrane-bound proteins. This presents an appealing approach to functionalizing synthetic polymer fiber scaffolds for applications in tissue and cell engineering.

\section{Experimental section}

\subsection{Fabrication of PCL fibers}

PCL fibers were prepared with a $10 \% \mathrm{w} / \mathrm{v}$ solution of PCL (Polycaprolactone, $M_{\mathrm{W}}: 80 \mathrm{kDa}$, Sigma Aldrich, St. Louis, USA) in 1,1,1,3,3,3-Hexafluoro2-propanol (HFP, $M_{\mathrm{W}}$ : 168.04, Sigma Aldrich, St. Louis, USA) [20]. The solution was incubated at room temperature for a minimum of $6 \mathrm{~h}$, briefly vortexed, and electrospun at a flow rate of $20 \mu \mathrm{L} / \mathrm{min}$, a voltage of $12 \mathrm{kV}$, and a spinneret-to-ground distance of $12 \mathrm{~cm}$. The electrospun PCL fibers were collected on $0.25 \mathrm{~cm}^{2}$ silicon chips that were placed on top of the aluminum foil collector plate. A portion of the silicon chips that collected electrospun PCL fibers immediately underwent an air-plasma treatment (Harrick Plasma, Model PDC-001, Ithaca, USA) for 10 min under vacuum, generating plasma-treated PCL fibers for further use [20].

\subsection{Formation of CSS-PCL fibers}

CSS was dissolved in $100 \% \mathrm{EtOH}$ at the desired concentrations (e.g., 1.0, and 5.0\% w/v); $200 \mu \mathrm{L}$ of DI water was added to the $4 \mathrm{~mL}$ CSS solution, permitting the occurrence of hydrolysis and polymerization [19, 21]; silicon chips that collected freshly plasma-treated PCL fibers were each placed in a single well of a 48 -well plate; a $500 \mu \mathrm{L}$ solution of CSS was added to each well, submerging the plasmatreated PCL fibers. The 48-well plate was sealed, and placed under humidified conditions, allowing CSS to hydrolyze, forming vesicles and conjugating onto PCL fibers. The resulting CSS-PCL fibers were rinsed three times with DI water prior to use.

The water contact angles were assessed for electrospun PCL, plasma-treated PCL, and CSS-PCL fibers to evaluate changes in the hydrophilicity of fiber scaffolds due to air plasma treatment and CSS coating. A $10 \mu \mathrm{L}$ droplet of DI water was placed on each type of fiber scaffolds $(n=3)$ and measured with instrumentation FTA-200 (RS-170 camera, First Ten Angstroms, Portsmouth, USA). The water contact angle was determined with FTA-32 software (First Ten Angstroms, Portsmouth, USA), and presented as mean \pm standard error for each fiber type.

\subsection{Characterization of CSS-PCL fibers}

$\mathrm{DiO}$ (3,3'-Dioctadecyloxacarbocyanine perchlorate, Sigma Aldrich, St. Louis, USA), which is frequently used as a fluorescent probe of lipid bilayers [25], was utilized as a model system to study the CSS-mediated immobilization of membrane-bound molecules on CSS-PCL fibers. A working solution of $\mathrm{DiO}$ was prepared in $100 \% \mathrm{EtOH}$ at a final concentration of $30 \mu \mathrm{g} / \mathrm{mL}$. Silicon chips that collected CSS-PCL or PCL fibers were each placed in a single well of a 48well plate. A $300 \mu \mathrm{L}$ working solution of $\mathrm{DiO}$ was added to each well, and the fiber samples were incubated for $1 \mathrm{~h}$ in the dark and at room temperature. For a control study, the fiber samples were first exposed to $1 \%$ bovine serum albumin (BSA) solutions for $1 \mathrm{~h}$ at room temperature to block the fibers from interacting with $\mathrm{DiO}$, and then incubated with $\mathrm{DiO}$ solutions for $1 \mathrm{~h}$. The fiber specimens were washed with $100 \%$ EtOH three times, and submerged 
in fresh $\mathrm{EtOH}$, before the relative fluorescence intensities of immobilized DiO were read using a microplate reader (Synergy 2 SL Luminescence Microplate Reader, BioTek, Winooski, USA) at an excitation wavelength of $485 \mathrm{~nm}$ and an emission wavelength of $508 \mathrm{~nm}$.

Raman spectroscopy was also employed to characterize CSS-PCL fibers, in comparison to the PCL control. The Raman spectra for each sample were collected from 20 scans and 60 seconds per scan on a micro-Raman system (Thermo Almega, Thermo Fisher Scientific, Waltham, USA), using a solid-state laser with a wavelength of $532 \mathrm{~nm}$, and a thermoelectrically cooled CCD detector. The laser is partially polarized with a resolution of $4 \mathrm{~cm}^{-1}$ and a spot size of $1 \mu \mathrm{m}$.

\subsection{Anti-CD20 immobilization on CSS-PCL fibers}

The immobilization of anti-CD20 antibodies on the CSS-PCL fibers was examined, in comparison to the PCL and plasma-treated PCL controls. Following a protocol previously reported $[19,26]$, silicon chips that collected electrospun fibers were each placed in a single well of a 48-well plate, rinsed with PBS three times, exposed to $200 \mu \mathrm{L}$ of a $10 \mu \mathrm{g} / \mathrm{mL}$ anti-CD20 solution, and incubated for $90 \mathrm{~min}$ at $37^{\circ} \mathrm{C}$. After the incubation period the solution was collected and placed in fresh wells of a new and sterile 96-well plate. The fiber specimens and wells were rinsed three times with PBS. The amount of unbound anti-CD20 remaining in the solution and washes from the same specimen was detected with a microplate reader (Synergy 2 SL Luminescence Microplate Reader, BioTek, Winooski, USA) at an excitation wavelength of $460 / 40 \mathrm{~nm}$ and an emission wavelength of $590 / 10 \mathrm{~nm}$.

\subsection{Cell capture}

After anti-CD20 immobilization, the fiber specimens were incubated in a $0.1 \% \mathrm{w} / \mathrm{v}$ solution of BSA in $1 \times$ PBS for $1 \mathrm{~h}$ at $37^{\circ} \mathrm{C}$ to block unbound reaction sites, washed with $1 \times$ PBS three times, and seeded with Granta-22 B-cell lymphomas at a density of $2 \cdot 10^{4}$ cells per sample. The functionalized fiber specimens were incubated for $45 \mathrm{~min}$ to allow for cell capture. After cell capture the specimens were washed three times with $1 \times$ PBS and subjected to a 15 -min incubation in $4 \% \mathrm{w} / \mathrm{v}$ paraformaldehyde. The captured cells were treated with Triton-X prior to being stained with ProLong ${ }^{\circledR}$ Gold Antifade with DAPI (Thermo Fisher Scientific, Waltham, USA) against the cell nuclei, and imaged the following day with a Nikon fluorescent microscope.

\subsection{Statistical analysis}

A Student's $t$-test was computed between each fiber type to determine statistical significance for DiO immobilization, antibody immobilization, and cell capture efficiencies. $P$-values less than 0.05 were considered statistically significant whereas anything greater than 0.05 was considered statistically insignificant.

\section{Results and discussion}

As shown in Figure 1, air-plasma treatment induces chemical modification of electrospun PCL fibers and creates hydroxyl groups on the fiber surfaces, transforming hydrophobic PCL fiber scaffolds with a water contact angle of $93.3 \pm 2.3^{\circ}$ into hydrophilic fiber scaffolds with a water contact angle of $35.1 \pm 2.2^{\circ}$. At a concentration of $1 \sim 5 \% \mathrm{w} / \mathrm{w}$ that exceeds the critical micelle concentration of lipid [27], CSS in ethanol can be hydrolyzed in the presence of a small amount of water and the hydrolyzed CSS molecules form lipid vesicles [28]. In a polar solvent, CSS vesicles adopt bilayer structures, in which their hydroxyl groups are exposed to solvents [28]. When the plasma-treated PCL fibers are immersed in CSS solutions, CSS vesicles would be immobilized on the fibers. It has been reported that PCL fibers can be modified by air-plasma treatment and chemical conjugated with laminin [24]. Here, PCL fibers can be

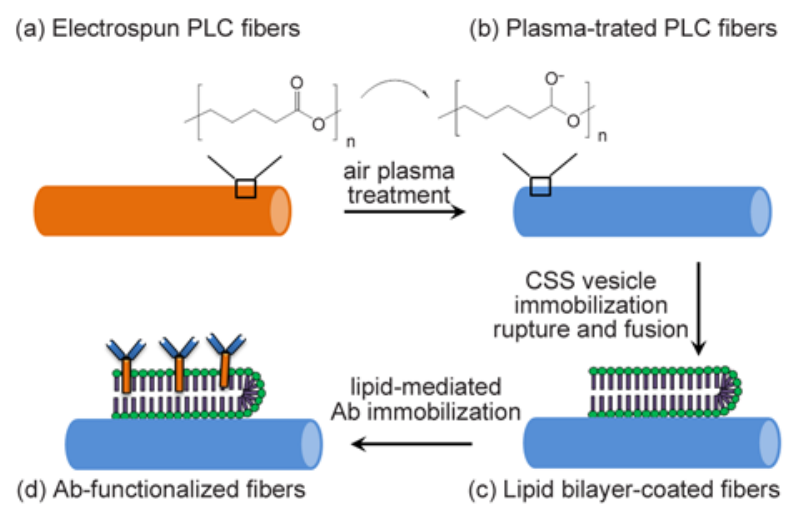

Figure 1. Schematic illustration of electrospinning of hydrophobic PCL fibers (a), air-plasma treatment of PCL fibers and generation of hydrophilic fibers (b), CSS vesicle immobilization, rupture and fusion on the plasma-treated PCL fibers (c), and antibody immobilization on and functionalization of the PCL fibers (d) 
conjugated with CSS after air plasma treatment, improving the immobilization of CSS vesicles. Following a mechanism proposed by others [29, 30], the immobilized vesicles may rupture and fuse into a continuously supported lipid bilayer (Figure 1c). As suggested by others [29], the spreading of CSS bilayers on the fiber surfaces may provide a natural environment for the oriented immobilization of membrane-bound proteins such as antibodies under nondenaturing conditions (Figure 1d).

$\mathrm{DiO}$ was used as a lipid-membrane probe in the initial study to verify the CSS coating of the CSS-PCL fibers in comparison to the PCL control. The CSSPCL fibers were obtained by incubating the plasmatreated PCL fibers in either a 1 or $5 \% \mathrm{w} / \mathrm{v}$ CSS solution overnight. The relative fluorescent intensity (RFI) of immobilized DiO was determined to be $45.8 \pm 5.76$ on the CSS-PCL fibers and $13.5 \pm 3.6$ on the PCL control (Figure 2). Compared to the PCL control, a 2.4-fold increase in RFI may be due to (1) an increase in the amount of DiO immobilized on the CSS-PCL fibers, (2) enhanced fluorescence of $\mathrm{DiO}$ in the presence of CSS membranes, or (3) both. As a lipid probe, $\mathrm{DiO}$ is fluorescent in the presence of lipid membranes. The lipid membranes of the CSS-PCL fibers may enhance $\mathrm{DiO}$ fluorescence in comparison to the PCL control. When the CSS-PCL fibers and the PCL control were exposed to BSA for $1 \mathrm{~h}$, the fiber surfaces would be partially covered with BSA molecules and blocked from interacting with DiO. After the BSA treatment, the RFI of DiO was measured to be $17.86 \pm 1.12$ on the CSS-PCL fibers and $9.2 \pm 2.4$ on the PCL control. The BSA treatment leads to a $32 \%$ reduction in RFI on the PCL control and a $61 \%$ reduction on the CSS-PCL fibers. This suggests that the BSA treatment has more detrimental effects on the lipid-mediated immobilization of

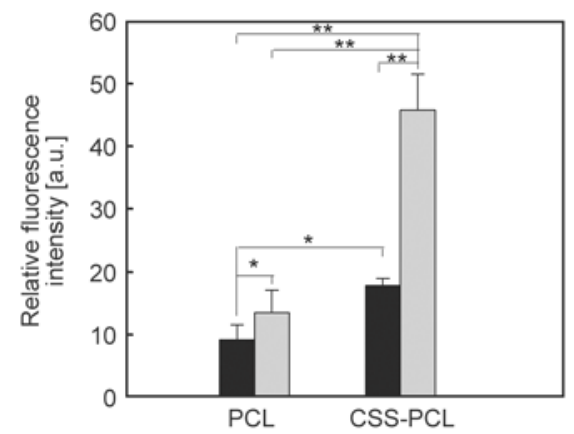

Figure 2. Relative fluorescence intensities (RFI) of DiO immobilized on the PCL control and CSS-PCL fibers, which were treated (gray) or not treated (black) with BSA. ${ }^{*} p \leq 0.05 ;{ }^{* *} p \leq 0.01$.
DiO on the CSS-PCL fibers than the hydrophobic immobilization of $\mathrm{DiO}$ on the PCL control.

Raman spectroscopy was further employed to characterize the CSS-PCL fibers. The use of a $100 \times$ objective generates a sampling spot of $1 \mu \mathrm{m}$ in size, comparable to the diameters of PCL fibers [20]. This permits Raman spectroscopic analysis of single PCL or CSS-PCL fibers. In the spectral region of 600 $1800 \mathrm{~cm}^{-1}$, the PCL fibers display characteristic bands at $1725\left(\mathrm{C}=\mathrm{O}\right.$ stretching), 1462 and $1442\left(\mathrm{CH}_{2}\right.$ scissoring and wagging [31] and $\mathrm{CH}_{3}$ asymmetric bending [32]), 1305 and $1285\left(\mathrm{CH}_{2}\right.$ bending), 1110 (C-O-C asymmetric stretching [33]), and 1066 (C-O-C symmetric stretching [33]), $958\left(\mathrm{CH}_{3}\right.$ rocking [34]), 916, 868, and $713 \mathrm{~cm}^{-1}(\mathrm{C}=\mathrm{O}$ bending [33] $)$ (Figure 3). Compared to the PCL control, the CSSPCL-1 fibers did not show noticeable changes in Raman spectra. However, the DiO immobilization study clearly indicates the CSS coating of CSS-PCL-1 fibers. Likely, Raman spectroscopy conducted at a single spot of about $1 \mu \mathrm{m}$ in size does not possess the same detection sensitivity of the DiO assay that is performed on fiber specimens of $0.25 \mathrm{~cm}^{2}$ in size. When the CSS-PCL fibers were prepared by incubating plasma-treated PCL fibers with $5 \% \mathrm{w} / \mathrm{v}$ CSS solutions, new bands appeared at $1670(\mathrm{C}=\mathrm{O}$ amide $\mathrm{I})$, $877,851,801,736$, and $700 \mathrm{~cm}^{-1}$, which can be attributed to CSS' cholesterol portion [35]. This suggests that the use of $5 \% \mathrm{w} / \mathrm{v}$ solutions improves the total mass of CSS coated on PCL fibers for Raman detection. In addition to the characteristic bands of the cholesterol segment of CSS, the hydrolyzed tri-

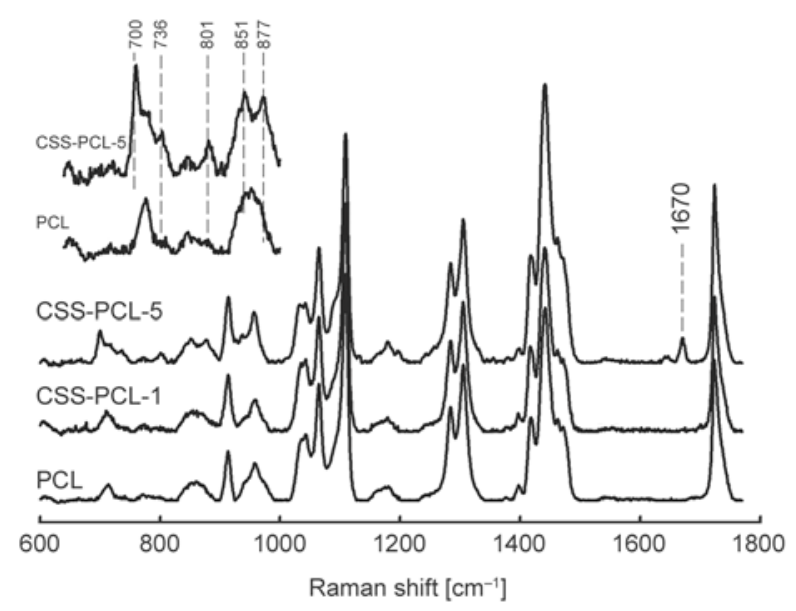

Figure 3. Raman spectra of CSS-PCL (i.e., CSS-PCL-1 and CSS-PCL-5) and PCL fibers. CSS-PCL-1 and CSS-PCL-5 fibers were obtained by incubating plasma-treated PCL fibers with 1 and 5\% w/v CSS solutions, respectively 
ethoxysilyl moieties may display peaks at 1092 (SiOC asymmetric stretching), 1046 (SiOSi asymmetric stretching), 948 (SiOC symmetric stretching), and $792 \mathrm{~cm}^{-1}$ (SiOSi symmetric stretching). However, those bands may be masked by the stronger bands of PCL at the similar locations.

Murine anti-CD20 was used to further investigate the ability of the CSS-PCL-1 fibers to immobilize membrane-bound proteins and retain protein functions. The amount of unbound anti-CD20 remaining in the solution was quantified (Figure $4 \mathrm{a}$ ) and the amount of anti-CD20 immobilized on the fiber specimens was calculated (Figure 4b). When exposed to $2 \mu \mathrm{g}$ anti-CD20 per sample, the amount of anti-CD20 remaining in the solution was evaluated to be $0.38 \pm 0.4,0.96 \pm 0.40$, and $0.31 \pm 0.21 \mu \mathrm{g}$ for the PCL, plasma-treated PCL, and CSS-PCL-1 fiber scaffolds, respectively. The percentage of immobilized antiCD20 was computed to be $81 \pm 12,55 \pm 18$, and $85 \pm 10 \%$ on the PCL, plasma-treated PCL, and CSSPCL-1 fiber scaffolds, respectively. The CSS-PCL-1 fibers immobilized more anti-CD20 than the plasmatreated PCL control but a comparable amount of anti-CD20 as the PCL control. However, difference in the amounts of anti-CD20 immobilized on the three fiber types is statistically insignificant.

As previously reported, the function retention of anti-CD20 immobilized on electrospun fibers can be evaluated by using a cell-capture assay [20]. Because anti-CD20 specifically recognizes CD20 phosphoprotein expressed on the surfaces of normal $\mathrm{B}$ lymphocytes and B-cell lymphomas [36, 37], Granta-22 B cells were used in the cell capture study. Due to their non-adherent nature, Granta-22 cells immobilized on fiber specimens via non-specific binding can be readily removed by PBS washing. Consequently, the capture of Granta-22 cells on fiber specimens is

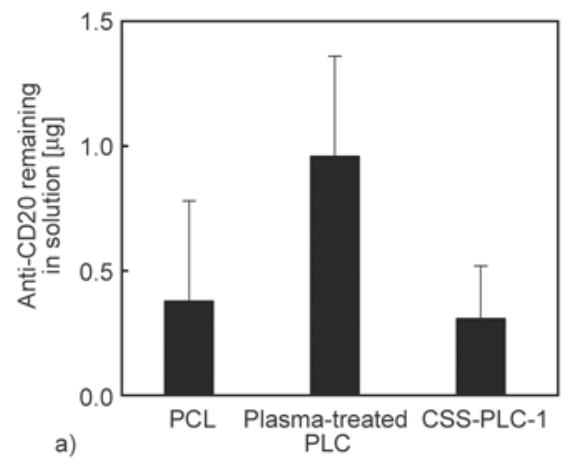

attributed solely to immobilized anti-CD20 that retains its cell-binding functions. The number density of Granta-22 cells immobilized on the fiber scaffolds was normalized using the PCL control, which captured $28.8 \pm 6.4$ cells per $\mathrm{mm}^{2}$. The CSS coating on plasma-treated PCL fibers improves the ability of the anti-CD20 functionalized fiber scaffolds to capture Granta-22 cells. Compared to the PCL control, the CSS-PCL-1 fiber scaffolds capture 35\% more cells and the CSS-PCL-5 fiber scaffolds captures 139\% more cells (Figure 5). A representative image of the CSS-PCL-5 fiber scaffolds with captured cells was shown in Figure 6. Because the CSS-PCL and PCL fiber scaffolds immobilized a comparable amount of anti-CD20, the increased cell capture by the CSS-coated fibers is likely due to the improved antibody orientation and function retention that is facilitated by CSS lipid membranes. In comparison to the CSS-PCL-1 fiber scaffolds, the CSS-PCL-5 fiber scaffolds display a better ability to capture cells.

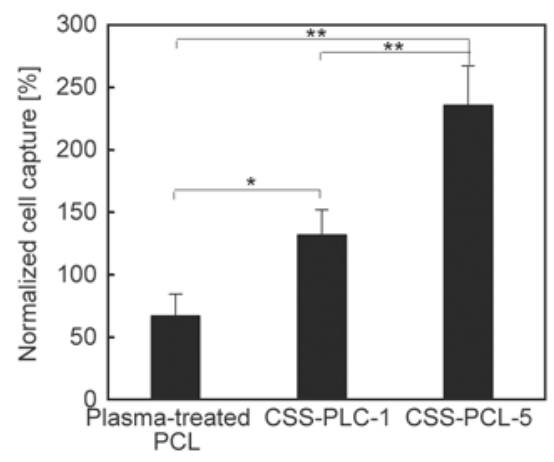

Figure 5. The normalized number of Granta-22 cells captured on the plasma-treated PCL, CSS-PCL-1, and CSS-PCL-5 fiber scaffolds. The CSS-PCL-1 and CSS-PCL-5 fibers were obtained by incubating plasma-treated PCL fibers with 1 and $5 \% \mathrm{w} / \mathrm{v}$ CSS solutions, respectively. All the fiber scaffolds were functionalized using anti-CD20 for cell capture. ${ }^{*} p<0.05,{ }^{* *} p<0.01$.

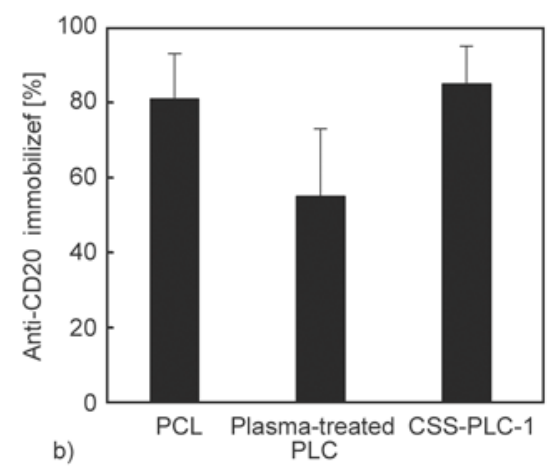

Figure 4. Anti-CD20 was immobilized onto the CSS-PCL-1 fibers and the PCL and plasma-treated PCL controls. The amount of unbound anti-CD20 remaining in solution was measured (a), and the percentage of anti-CD20 immobilized was calculated (b). Among the three fiber groups, $p>0.05$. 


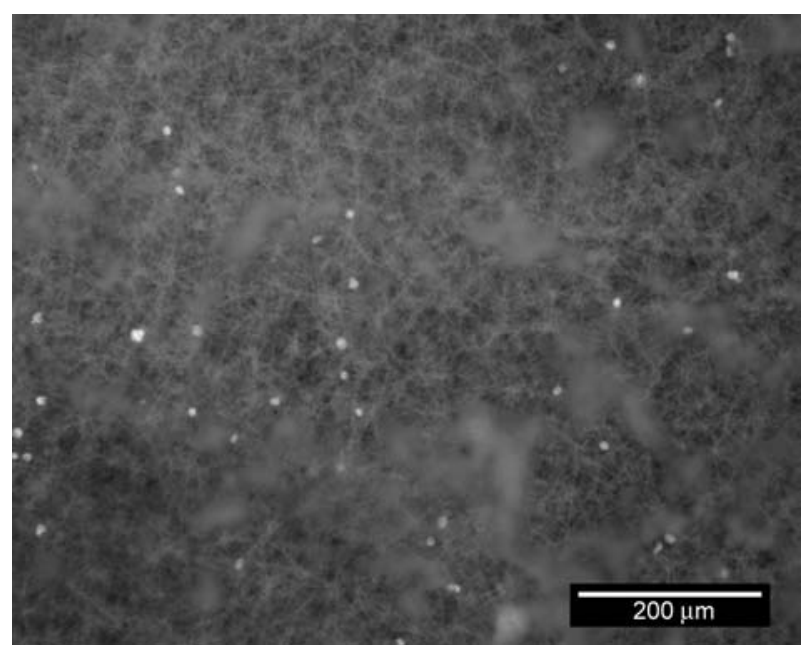

Figure 6. Optical images of the CSS-PCL-5 fibers with captured Granta-22 B cells. The cells were stained with ProLong ${ }^{\circledR}$ Gold Antifade with DAPI against the cell nuclei.

It is likely that the use of $5 \% \mathrm{w} / \mathrm{v}$ CSS solutions to treat plasma-treated PCL fibers improves CSS coating, which, in turn, enhances the oriented immobilization and function retention of anti-CD20. The use of more concentrated ( $>5 \% \mathrm{w} / \mathrm{v})$ CSS solutions to treat plasma-treated PCL fibers was not pursued due to concerns of precipitation. Compared to the PCL control, the plasma-treated PCL fiber scaffolds are less effective in capturing cells. This may be due to the fact that the hydrophilic fibers immobilize less anti-CD20 and/or are less efficient in retaining antibody functions than the hydrophobic PCL fibers.

\section{Conclusions}

A simple and facile approach has been developed to functionalize electrospun PCL fibers. Specifically, PCL fibers are treated using air plasma and incubated with ethanol solutions of CSS at a concentration of $1 \sim 5 \% \mathrm{w} / \mathrm{v}$, leading to the immobilization of CSS lipid bilayers on the plasma-treated PCL fibers. The CSS immobilization on the fibers is facilitated by chemical conjugation and confirmed by a DiO immobilization assay and micro-Raman spectroscopy. The lipid environments of the CSS-PCL fibers improve the oriented immobilization and function retention of membrane-bound proteins such as antibodies. This view is supported by results from studies on the immobilization of anti-CD20 antibodies on the CSS-PCL fibers and the capture of Granta-22 cells using the anti-CD20 functionalized CSS-PCL fiber scaffolds. Although beyond the scope of the present study, the CSS-PCL fiber scaffolds can be readily functionalized by other membrane-bound proteins to acquire cell-specific functions. The mechanically robust PCL fibers conferred with cellspecific functions may find important applications in cell and tissue engineering.

\section{Acknowledgements}

This work was supported by the US National Institutes of Health (EB009160) and National Science Foundation (CMMI0856215).

\section{References}

[1] Zhang S.: Fabrication of novel biomaterials through molecular self-assembly. Nature Biotechnology, 21, 1171-1178 (2003).

DOI: $10.1038 / \mathrm{nbt} 874$

[2] Beniash E., Hartgerink J. D., Storrie H., Stendahl J. C., Stupp S. I.: Self-assembling peptide amphiphile nanofiber matrices for cell entrapment. Acta Biomaterialia, 1, 387-397 (2005).

DOI: $10.1016 /$ j.actbio.2005.04.002

[3] Huang L., Nagapudi K., Apkarian R. P., Chaikof E. L.: Engineered collagen-PEO nanofibers and fabrics. Journal of Biomaterials Science, Polymer Edition, 12, 979993 (2001).

DOI: $10.1163 / 156856201753252516$

[4] Li W-J., Laurencin C. T., Caterson E. J., Tuan R. S., Ko F. K.: Electrospun nanofibrous structure: A novel scaffold for tissue engineering. Journal of Biomedical Materials Research, 60, 613-621 (2002).

DOI: $10.1002 / \mathrm{jbm} .10167$

[5] Buttafoco L., Kolkman N. G., Engbers-Buijtenhuijs P., Poot A. A., Dijkstra P. J., Vermes I., Feijen J.: Electrospinning of collagen and elastin for tissue engineering applications. Biomaterials, 27, 724-734 (2006). DOI: 10.1016/j.biomaterials.2005.06.024

[6] Qiu W., Huang Y., Teng W., Cohn C. M., Cappello J., Wu X.: Complete recombinant silk-elastinlike proteinbased tissue scaffold. Biomacromolecules, 11, 32193227 (2010).

DOI: $10.1021 / \mathrm{bm} 100469 \mathrm{w}$

[7] Genové E., Shen C., Zhang S., Semino C. E.: The effect of functionalized self-assembling peptide scaffolds on human aortic endothelial cell function. Biomaterials, 26, 3341-3351 (2005).

DOI: $10.1016 /$ j.biomaterials.2004.08.012

[8] Woolfson D. N., Mahmoud Z. N.: More than just bare scaffolds: Towards multi-component and decorated fibrous biomaterials. Chemical Society Reviews, 39, 3464-3479 (2010). DOI: $10.1039 / \mathrm{c} 0 \mathrm{cs} 00032 \mathrm{a}$

[9] Chwalek K., Tsurkan M. V., Freudenberg U., Werner C.: Glycosaminoglycan-based hydrogels to modulate heterocellular communication in in vitro angiogenesis models. Scientific Reports, 4, 4414/1-4414/8 (2014). DOI: $\underline{10.1038 / \text { srep04414 }}$ 
[10] Lee S. J., Liu J., Oh S. H., Soker S., Atala A., Yoo J. J.: Development of a composite vascular scaffolding system that withstands physiological vascular conditions. Biomaterials, 29, 2891-2898 (2008).

DOI: 10.1016/j.biomaterials.2008.03.032

[11] Gu S-Y., Wang Z-M., Ren J., Zhang C-Y.: Electrospinning of gelatin and gelatin/poly(L-lactide) blend and its characteristics for wound dressing. Materials Science and Engineering: C, 29, 1822-1828 (2009).

DOI: $10.1016 /$ j.msec.2009.02.010

[12] Merkle V. M., Zeng L., Slepian M. J., Wu X.: Coreshell nanofibers: Integrating the bioactivity of gelatin and the mechanical property of polyvinyl alcohol. Biopolymers, 101, 336-346 (2013).

DOI: $10.1002 /$ bip.22367

[13] Zhang Y. Z., Venugopal J., Huang Z-M., Lim C. T., Ramakrishna S.: Characterization of the surface biocompatibility of the electrospun PCL-collagen nanofibers using fibroblasts. Biomacromolecules, 6, 2583-2589 (2005).

DOI: $10.1021 / \mathrm{bm} 050314 \mathrm{k}$

[14] Kwon I. K., Matsuda T.: Co-electrospun nanofiber fabrics of poly(L-lactide-co- $\varepsilon$-caprolactone) with type I collagen or heparin. Biomacromolecules, 6, 2096-2105 (2005).

DOI: $10.1021 / \mathrm{bm} 050086 \mathrm{u}$

[15] Chiu J. B., Liu C., Hsiao B. S., Chu B., Hadjiargyrou M.: Functionalization of poly(L-lactide) nanofibrous scaffolds with bioactive collagen molecules. Journal of Biomedical Materials Research Part A, 83, 1117-1127 (2007).

DOI: $10.1002 / \mathrm{jbm} . \mathrm{a} .31279$

[16] Guex A. G., Hegemann D., Giraud M. N., Tevaearai H. T., Popa A. M., Rossi R. M., Fortunato G.: Covalent immobilisation of VEGF on plasma-coated electrospun scaffolds for tissue engineering applications. Colloids and Surfaces B: Biointerfaces, 123, 724-733 (2014).

DOI: $10.1016 /$ j.colsurfb.2014.10.016

[17] Kim K., An H. J., Jun S-H., Kim T-J., Lim S. A., Park G., Na H. B., Park Y. I., Hyeon T., Yee C., Bluestone J. A., Kim J., Lee K-M.: Single step isolation and activation of primary $\mathrm{CD}^{+}$T lymphocytes using alcohol-dispersed electrospun magnetic nanofibers. Nano Letters, 12, 4018-4024 (2012).

DOI: $10.1021 / \mathrm{nl} 301388 \mathrm{~d}$

[18] Jun S-H., Kim K., An H. J., Kim B. C., Sonn C. H., Kim M., Doh J., Yee C., Lee K-M., Kim J.: Ethanol-dispersed polymer nanofibers as a highly selective cell isolation and release platform for $\mathrm{CD}^{+}$T lymphocytes. Advanced Functional Materials, 22, 4448-4455 (2012). DOI: $10.1002 / \mathrm{adfm} .201200657$

[19] Zha Z., Cohn C., Dai Z., Qiu W., Zhang J., Wu X.: Nanofibrous lipid membranes capable of functionally immobilizing antibodies and capturing specific cells. Advanced Materials, 23, 3435-3440 (2011).

DOI: $10.1002 /$ adma.201101516
[20] Cohn C., Leung S. L., Zha Z., Crosby C., Teng W., Wu X.: Comparative study of antibody immobilization mediated by lipid and polymer fibers. Colloids and Surfaces B: Biointerfaces, 134, 1-7 (2015). DOI: 10.1016/j.colsurfb.2015.06.021

[21] Zhang J., Cohn C., Qui W., Zha Z., Dai Z., Wu X.: Atomic force microscopy of electrospun organic-inorganic lipid nanofibers. Applied Physics Letters, 99, 103702/1-103702/3 (2011).

DOI: $10.1063 / 1.3635783$

[22] Venugopal J., Ma L. L., Yong T., Ramakrishna S.: In vitro study of smooth muscle cells on polycaprolactone and collagen nanofibrous matrices. Cell Biology International, 29, 861-867 (2005).

DOI: $10.1016 /$ j.cellbi.2005.03.026

[23] Shin M., Ishii O., Sueda T., Vacanti J. P.: Contractile cardiac grafts using a novel nanofibrous mesh. Biomaterials, 25, 3717-3723 (2004).

DOI: $10.1016 /$ j.biomaterials.2003.10.055

[24] Zander N. E., Orlicki J. A., Rawlett A. M., Beebe T. P.: Quantification of protein incorporated into electrospun polycaprolactone tissue engineering scaffolds. Acs Applied Materials and Interfaces, 4, 2074-2081 (2012). DOI: $10.1021 / \mathrm{am} 300045 \mathrm{y}$

[25] Honig M. G., Hume R. I.: Dil and DiO: versatile fluorescent dyes for neuronal labelling and pathway tracing. Trends in Neurosciences, 12, 333-341 (1989). DOI: 10.1016/0166-2236(89)90040-4

[26] Zha Z., Jiang L., Dai Z., Wu X.: A biomimetic mechanism for antibody immobilization on lipid nanofibers for cell capture. Applied Physics Letters, 101, 193701/1193701/4 (2012). DOI: $10.1063 / 1.4766191$

[27] McKee M. G., Layman J. M., Cashion M. P., Long T. E.: Phospholipid nonwoven electrospun membranes. Science, 311, 353-355 (2006). DOI: $10.1126 /$ science. 1119790

[28] Ma Y., Dai Z., Zha Z., Gao Y., Yue X.: Selective antileukemia effect of stabilized nanohybrid vesicles based on cholesteryl succinyl silane. Biomaterials, 32, 9300-9307 (2011).

DOI: 10.1016/j.biomaterials.2011.08.043

[29] Sackmann E.: Supported membranes: Scientific and practical applications. Science, 271, 43-48 (1996). DOI: $10.1126 /$ science. 271.5245 .43

[30] Kam L., Boxer S. G.: Formation of supported lipid bilayer composition arrays by controlled mixing and surface capture. Journal of the American Chemical Society, 122, 12901-12902 (2000).

DOI: $10.1021 / \mathrm{ja} 0034038$

[31] Koenig J. L.: Raman spectroscopy of biological molecules: A review. Journal of Polymer Science: Macromolecular Reviews, 6, 59-177 (1972). DOI: $10.1002 /$ pol.1972.230060102

[32] Barth A., Zscherp C.: What vibrations tell about proteins. Quarterly Reviews of Biophysics, 35, 369-430 (2002).

DOI: $10.1017 / \mathrm{S} 0033583502003815$ 
[33] Porwal V., Singh M., Chaturvedi D., Tandon P., Gupta V. D.: Vibrational dynamics and heat capacity in poly (L-lactic acid). Journal of Polymer Science Part B: Polymer Physics, 48, 175-182 (2010).

DOI: $10.1002 /$ polb. 21886

[34] Monti P., Taddei P., Freddi G., Asakura T., Tsukada M.: Raman spectroscopic characterization of Bombyx mori silk fibroin: Raman spectrum of silk I. Journal of Raman Spectroscopy, 32, 103-107 (2001).

DOI: $10.1002 /$ jrs.675

[35] Lippert J. L., Peticola W. L.: Laser Raman investigation of the effect of cholesterol on conformational changes in dipalmitoyl lecithin multilayers. Proceedings of the National Academy of Sciences of the United States of America, 68, 1572-1576 (1971).

DOI: $10.1073 /$ pnas.68.7.1572
[36] Reff M. E., Carner K., Chambers K. S., Chinn P. C., Leonard J. E., Raab R., Newman R. A., Hanna N., Anderson D. R.: Depletion of B cells in vivo by a chimeric mouse human monoclonal antibody to CD20. Blood, 83, 435-445 (1994)

[37] Davis T. A., Czerwinski D. K., Levy R.: Therapy of Bcell lymphoma with anti-CD20 antibodies can result in the loss of CD20 antigen expression. Clinical Cancer Research, 5, 611-615 (1999). 